\title{
The Digital Age: A Feminist Future for the Queer African Woman
}

\author{
Nyx McLean and Tiffany Kagure Mugo
}

\begin{abstract}
How can digital spaces make possible a feminist future for the queer African woman? Writing as the editors of a South African queer online space, HOLAA!, this article aims to draw attention to and discuss queer digital communities and how they afford the queer African woman the space to express her lived experiences. The article further examines how digital spaces create these possibilities for public and political expression. Lastly, the authors present what they consider to be a feminist future for the queer African woman, and that it is within this future that the rights of queer women can be protected nationally and internationally as the conversations that fight erasure, exclusion and the denial of rights occur.
\end{abstract}

\section{Introduction}

How can digital spaces make possible a feminist future for the queer African woman? Writing as the editors of a South African queer online space, HOLAA!, this article aims to draw attention to and discuss queer ${ }^{1}$ digital communities and how they afford the queer African woman the space to express her lived experiences. The digital space makes it possible for voices that may not have been present in the public sphere prior to the existence of social networking sites, such as Facebook (Goby 2003), to be heard and viewed publicly. The internet and its platforms allow for people to be exposed to viewpoints that are not their own and to be held accountable for the values they espouse, as well as having these challenged, publicly. This makes for a richer public sphere (McLean 2013, 2014; Nip 2004), and for opportunities to construct counter-publics and counter-discourses. Through the example of HOLAA!, this article examines how digital spaces create these possibilities for public and political expression.

Prinsloo, Moletsane and McLean (2012), in their research on lesbian use of the internet, put forward Dahlberg's (2007) proposal that the internet creates the space for counter-publics. A public is ideological and maintained through discourse. It is unable to exist outside of the discourses that inhabit it (Dahlberg 2007; Warner 2005). Warner states 'some publics are defined by their tension with larger publics' (2005: 56). This public in conflict with the larger project is then understood as being in breach with the 'rules obtained in the world at large, being structured by alternative dispositions or protocols' - this is a counter-public (Warner 2005: 56). Fraser suggests that for marginalised groups, such as lesbian, gay, bisexual, transgender, intersex, asexual and queer (LGBTIAQ) persons, it is in their interest to form 'alternative publics' or 'subaltern counterpublics' (2007: 497). These subaltern counter-publics are spaces through which groups can create and distribute counter-discourses in order to form and assert their own interpretation of their identities and interests (Fraser 2007).

One essential purpose of counter-publics is to introduce new or alternative discursive positions into public spaces where they are able to be publicly opposed or challenged (Fraser 2007). An example of this is HOLAA!, a website that seeks to provide a digital space for queer African women.

\section{HOLAA!}

Marginalised communities, such as queer communities, find the internet a safer space for communication and identity formation. This is especially acute within the African context where many find offline spaces sparse, hostile and in some cases dangerous. HOLAA! seeks to add to these safe spaces on the continent, and in doing so can be considered as providing space for the formation of counter-publics, and a counter-public in and of itself.

Five categories create a hub to guide online content: Gender and Identit), Culture and Religion (Queerly Cultural, 
Queerly Spiritual), Sex and Relationships, Afro-Queer Politics and Afro-Queer Wisdom.

- Gender and Identity: This category is for those of alternative sexualities and who may term themselves 'genderqueer' to speak of their unique experiences. These experiences are often silenced in the greater rhetoric on the African continent that focuses on heteronormative expressions of sexuality and gender.

\section{- Culture and Religion (Queerly Cultural, Queerly} Spiritual): This arena can at times be the most tenuous to manoeuvre as within the African context ideas of culture and religion can be somewhat immovable and seemingly 'cast in stone'. The section allows for an exploration of how those who have held cultural and religious beliefs seek to reconcile those beliefs with their sexuality, sexual practices, gender and identity.

- Sex and Relationships: In Africa, issues of sex, sexuality and relationships are rarely discussed within the heterosexual realm and much less so in reference to non-heteronormative relationships. Content in this section is on matters such as polyamory, safe sex between two women, having regular orgasms, 'corrective dating', drug use within a relationship and same-sex domestic violence.

- Afro-Queer Politics: This section seeks to deal with sexual politics on the African continent, an increasingly contentious issue. From issues such as the 'politics of pride', to tackling matters within the legislative and sociopolitical realm (for example, Uganda's Anti-Homosexuality Bill) it provides an alternative lens to those already proving dominant on the international political stage.

Afro-Queer Wisdom: This section seeks to document and to begin new conversations on matters often silenced within the public sphere. The idea here is to generate information from within HOLAA! and through calls for content which ensures that the information that is circulated is also generated by those who visit the site.

These general groupings can be unpacked further by looking at the content within. Within the realm of religion and culture one post tackles the issue of being persecuted by religious figures on account of her religion. The post 'If I Am a Sinner then We Both Are' uses poetry to grapple with being judged on account of the author's sexuality while condemning the act of 'frightening people into obedience' with 'stories of life after death'.?

The idea of policing sexuality, as well as the sexual act itself, is continued with the post 'Deliver Us from Pleasure: An Experience of the Jesus Wedge'. ${ }^{3}$ Within this post a woman speaks of her experience with a Christian woman who felt constant shame, which obstructed her from feeling intimacy and ecstasy with another woman as she felt she would be condemned to 'eternal damnation'. The writing is an exploration of the effect of religious zeal within Nigeria on sexuality and the lens through which to view the experiences that come with expressing alternative sexualities.

Through the posting of various articles the site covers an array of topics, with all this material having been produced by those within the community. This is a key element to the way in which this particular platform functions. From issues pertaining to sexual health with posts such as 'Getting it Right: LGBT Women and HIV/Aids's to socioeconomic issues as tackled in the post 'Sex Work in the Lesbian Community', ${ }^{5}$ fringe issues are tackled and debated in the voices of those who occupy these 'fringe spaces'.

They are outlined in a way that allows for others within these spaces to identify and thus engage with the various matters. People are able to come to the fore and speak on everything from the political ('Gender, Identity and Politics: Why I Won't be Protesting the Cancellation of Joburg Pride') ${ }^{6}$ to the social and everyday ('Existencia Lesbica Afrocolobiana'). ${ }^{7}$ Subsequently, those who submit content and those who see the submissions are able to carve out a space through a sense of engagement with what they deem important to them in a way they choose.

The act of chronicling alternative experiences from around Africa and creating a counter-public through doing this creates a sense of empowerment and embodiment not only for those producing the content but also for those consuming it. This creation can be utilised as a basis on which one can seemingly 'carve out an existence' in the greater conversation rather than being confined to the fringes. HOLAA! is one of many online platforms that has carved out a space that allows for more voices to tell their stories, to reconstruct the narrative of queer lived experiences and to expand the margins. 


\section{Sharing stories, speaking collectively}

The internet and the manner in which it is used can create spaces for queer women to express themselves and to seek out other queer women. This seeking out of like identities may enable queer women to share stories of their lived experiences, to build on a shared narrative to create a community and to empower people to speak collectively. This further allows for knowledge sharing and knowledge production from within the community, not without, in a way that sees knowledge being created and not imposed upon queer identities.

In a society where queer identities have been rendered invisible and are policed into silence through persecution, there is very little intergenerational knowledge sharing. The internet allows for the archiving of content and what becomes a historical telling and collection of narratives which may be passed on from one generation of queer women to the next so that future generations of queer women may not feel that they are the only ones carving out an identity. Knowing that they are not alone and that there are other queer women is an emboldening moment.

Queer women, especially within Africa, may find that their stories are underrepresented and when they are spoken of, it is through one major narrative, that of homophobia and, specifically, corrective rape. This needs to begin to shift towards more positive and accurate representations and narratives of queer women that will allow them to take control of the narrative. This can aid in the reshaping of how queer African women are viewed, read and understood by their peers, their communities, their governments and the international community. This, in essence, forms part of a larger project to counter the narratives that come out of the continent that are primarily written by those removed from the experiences of people who live in Africa. This begins the work of levelling the ground for better engagement between the global North and the global South.

Geographic spaces do not always facilitate the meeting of queer women because of social, political and government responses to homosexuality and queer desire. Geographic spaces are often unsafe for queer bodies to navigate, let alone gather in. Because of social and political circumstances, the digital environment can provide a shelter and safe space for identities to re-energise, collaborate and gather in such as the HOLAA! site and social media communities.
In a society where queer identities are persecuted, ignored or made invisible, queer African women may increasingly turn to digital spaces to seek out a feminist future for themselves and those who will follow. Digital feminist spaces provide the platform needed for queer African women to have: an arena to speak of their experiences and their desires without fear of persecution or violence; protection from homophobic laws and criminal justice systems; the ability to seek out health care and information without fear of discrimination; access to resources and knowledge that will improve their quality of life; a place where they can mobilise to govern their bodies and have autonomy over their sexuality; and where they can begin to contribute to public life and social progress without making invisible their sexual and queer identities.

\section{Concluding remarks}

Although online spaces are increasingly becoming available, there is still a long way to go in terms of creating an extensive online space for African queer women. Compared to other online spaces such as those within the United States, which is populated by vlogs, blogs, and many prominent social media users on a whole host of platforms, the African queer female space is very much in its infancy. Although conversations about African queer women's issues are beginning to take place online, coupled with an increase in activity, there is still the space for many more players and many more voices.

Digital spaces have the potential to link the array of actors working on similar issues, but currently separated by location and other barriers. The need to connect and to see that 'I am not the only one' is a common theme among current occupiers within such digital spaces. There is a need to connect with those who you feel are 'just like you', be it through passive or active engagement with one another. Platforms such as blogs, Twitter and Facebook play a pivotal role in bringing queer African women together.

The online space allows for these connections to be made and there is space for bigger players to facilitate these connections and grow them. There are players emerging who have the potential to truly change the digital landscape, and we may find that these actors increasingly originate from civil society and lobbying spaces, and will use digital narratives to inform their lobbying, advocacy and policy work.

While the internet provides for necessary and alternative queer digital spaces, it also, however, 
provides communities and governments with the tools to monitor counter-publics. As the internet develops and governments become aware of online activity and the role it plays in governance, we may find that digital spaces increasingly become policed and politicised. Queer women and other marginalised identities will need to take into consideration their digital security and protection of personal information, particularly in light of various anti-homosexuality laws within various African countries. $^{8}$

Lastly, it must be remembered, in particular with reference to the African continent, that internet communities are "restricted to the digital "haves" (or at least those with digital social capital) rather than the "have nots" - and that offline class and social divides continue to exist online (Murthy 2008: 845).

We consider a feminist future to be where queer African women:

\section{Notes}

1 It is to be noted that we use the term queer here to denote non-heterosexual identities but do not employ the terms 'lesbian' or 'bisexual' because they are not always used as descriptors of nonheterosexual female sexuality in Africa (Payne and Davies 2012; Tamale 2011).

2 http://HOLAAfrica.org/if-i-am-a-sinner-thenwe-both-are/.

3 http://HOLAAfrica.org/deliver-us-frompleasure-an-experience-of-the-jesus-wedge/.

\section{References}

Dahlberg, L. (2007) 'The Internet, Deliberative Democracy, and Power: Radicalising the Public Sphere', International Fournal of Media and Cultural Politics 3.1: 47-64

Fraser, N. (2007) Transnationalizing the Public Sphere: On the Legitimacy and Efficacy of Public Opinion in a PostWestphalian World, http://eipcp.net/transversal/ 0605/fraser/en (accessed 17 October 2014)

Goby, V. (2003) 'Physical Space and Cyberspace: How do they Interrelate? A Study of Offline and Online Social Interaction Choice in Singapore', CyberPsychology and Behavior 6.6: 639-44

McLean, N. (2014) 'Considering the Internet as Enabling Queer Publics/Counter Publics', Spheres Fournal for Digital Cultures 1, University of Leuphana: Centre for Digital Cultures

McLean, N. (2013) 'Digital as an Enabler: A Case Study of the Joburg Pride 2012 Clash', Feminist Africa. E-spaces: E-politics 18: December: 25-42, http://cdc.leuphana.com/uploads/tx_
1 Can speak of their experiences and their desires without fear of persecution or violence;

2 Are protected by the law and the criminal justice system;

3 Are able to seek out health care without fear of discrimination;

4 Have access to resources and knowledge that will improve their quality of life;

5 Can govern their bodies and have autonomy over their sexuality; and

6 Can contribute to public life and social progress without making invisible their sexuality.

It is only within this future that the rights of queer women can be protected on the international and national level as the conversations that fight erasure, exclusion and the denial of rights occur.

4 http://HOLAAfrica.org/getting-it-right-lgbtwomen-and-hivaids/.

5 http://HOLAAfrica.org/sex-work-in-the-lesbiancommunity/.

6 http://HOLAAfrica.org/gender-identityand-politics-why-i-wont-be-protesting-thecancellation-of-joburg-pride-2/.

7 http://HOLAAfrica.org/existencia-lesbicaafrocolobiana/.

8 www.genderit.org/articles/marginalised-desiresand-internet.

dwwebjournal/spheres-1_McLean.pdf (accessed 8 February 2015)

Murthy, D. (2008) 'Digital Ethnography: An Examination of the Use of New Technologies for Social Research', Sociology 42: 837-55

Nip, J. (2004) 'The Relationship between Online and Offline Communities: The Case of the Queer Sisters', Media, Culture and Society 26.3: 409-28

Payne, R. and Davies, C. (2012) 'Introduction to the Special Section: Citizenship and Queer Critique', Sexualities 15.3-4: 251-56

Prinsloo, J.; Moletsane, R. and McLean, N. (2012) 'Cyberqueer SA: Reflections on Internet Usage by some Transgender and Lesbian South Africans', Gender and Media Diversity fournal 10: 139-46

Tamale, S. (2011) African Sexualities: A Reader, Cape Town: Pambazuka Press

Warner, M. (2005) Publics and Counterpublics, New York NY: Zone Books 